\title{
Cannabis administered during pregnancy: First- and second-generation effects in rats
}

\author{
P. A. FRIED and A. T. CHARLEBOIS \\ Carleton University, Ottawa, Ontario, Canada
}

\begin{abstract}
Female rats were administered cannabis smoke or placebo smoke throughout gestation, and the offspring were injected with tetrahydrocannabinol (THC) 2 months prior to mating. The male and female offspring of the experimental animals were significantly less fertile and had smaller reproductive organs. The experimental $F_{2}$ generation weighed less and were slower in some aspects of physiological development compared to $F_{2}$ control animals. Exposure to cannabis smoke as a fetus and THC as a young adult had a much greater effect on fertility than just injections of THC 2 months prior to mating.
\end{abstract}

The majority of studies investigating the effects of marihuana or its constituents on gravid animals have been directed at examining the incidence of fetal mortality and teratogenesis in the offspring (Braude, 1976). The data are not consistent. Malformation, resorption, and fetal stunting have been reported by some workers using both cannabis extract (Geber \& Schramm, 1969a, 1969b; Persaud \& Ellington, 1967, 1968) and $\Delta^{9}$-tetrahydrocannabinol (THC) (Harbison \& Mantilla-Plata, 1972; Joneja, 1976; Mantilla-Plata, Clewe, \& Harbison, 1973, 1975), a major psychoactive constituent of marihuana. On the other hand, other researchers failed to observe such effects (Fleischman, Hayden, Rosenkrantz, \& Baude, 1975; Fried, 1976; Gianustos \& Abbatiello, 1972; Miras, 1965). Although in these latter studies no frank teratogenesis was noted, a number of drug effects were observed including a reduction in maternal growth rate (Banerjee, Galbreath, \& Sofia, 1975; Borgen, Davis, \& Pace, 1971; Pace, Davis, \& Borgen, 1971), a slowing of some physiological and reflexive development (Borgen, Davis, \& Pace, 1973; Fried, 1976), and altered electrophysiological responses to THC when the offspring of gravid rats were administered cannabis smoke as young adults (Fried, 1976).

As with the issue of teratogenesis, the relationship between marihuana and reproductive behavior is not resolved. Studies have shown THC to both interfere (Merari, Berek, \& Plaves, 1973) and not interfere (Keplinger, Wright, Haley, Blank, Braude, \& Calandra, 1973; Wright, Smith, Keplinger, Calandra, \& Braude, 1976) with male rats' copulatory behavior. Researchers (Ling, Thomas, Usher, \& Singhal, 1973) have reported no effect of 4 days of administration of THC on gonadal activity of male rats, whereas

We thank L. Edds and J. Choynowski for assistance. This work was supported by grants from the Ontario Mental Health Foundation and the Medical Research Council.
Dixit et al. (Dixit, Sharma, \& Lohiya, 1974) found a complete arrest of spermatogenesis and a reduction in testicular and seminal vesicle weights following 45 days of administration of cannabis extract in mice. The findings of Dixit et al. were reversible. Female ovariectomized rats increased uterine weight following 14 days of THC treatment (Solomon, Cocchia, Gray, Shattuck, \& Vossmer, 1976). No changes in reproductive activity in chimpanzees were observed following long-term exposure to marihuana extract or THC (Grilly, Ferraro, \& Braude, 1974). In man, testosterone levels have been reported to be both unaltered (Cushman, 1975; Mendelson, Keuhnle, Ellingboe, \& Babor, 1974) and decreased (Kolodny, Masters, Kolodner, \& Toro, 1974) in long-term heavy users.

In the present experiment, we examined the reproductive organs and fertility of animals $\left(F_{1}\right)$ born to rats that were exposed to cannabis smoke throughout gestation, and examined the second-generation rats $\left(F_{2}\right)$ for evidence of frank and subtle teratogenesis.

\section{METHOD}

In a previous study (Fried, 1976), eight gravid rats of the Wistar strain were exposed to smoke from marihuana or placebo material (cannabis with cannabinoids removed) for $9 \mathrm{~min}$ a day throughout gestation by means of a respirator (Fried \& Nieman, 1973). The daily maximum amount of THC that each rat was exposed to was estimated to be approximately $3.3 \mathrm{mg}$. The offspring were cross-fostered, and the resulting four groups were designated as follows: (1) $\mathrm{CC}$, offspring born and raised by mothers exposed to smoke from control, placebo material; (2) CE, rats born to control mothers but raised by animals that had been exposed to cannabis smoke during gestation; (3) EC, animals born to rats that had been exposed to cannabis smoke but raised by rats that had inhaled smoke from placebo material; and (4) EE, animals born to and raised by rats that had inhaled cannabis smoke during gestation. These four groups were examined along numerous dimensions described elsewhere (Fried, 1976), the last of which consisted of recording electroencephalographic changes during 15 intraperitoneal injections of $8 \mathrm{mg} / \mathrm{kg}$ THC dissolved in a vehicle consisting of a mixture of Tween-80, saline, and 
Table 1

Fertility Data

\begin{tabular}{|c|c|c|c|c|c|c|c|c|c|}
\hline & & \multicolumn{2}{|c|}{ Group CC } & \multicolumn{2}{|c|}{ Group CE } & \multicolumn{2}{|c|}{ Group EC } & \multicolumn{2}{|c|}{ Group EE } \\
\hline & & Mean & $\mathrm{SE}$ & Mean & SE & Mean & SE & Mean & $\mathrm{SE}$ \\
\hline $\begin{array}{l}\text { Latency to } \\
\text { Organ Weig }\end{array}$ & lug Appearance & 24.63 & 5.99 & Organ Weights & 5.84 & 37.00 & $3.00^{*}$ & 31.0 & $5.9 *$ \\
\hline $\begin{array}{l}\text { Seminal } \\
\text { Testes } \\
\text { Prostrat } \\
\text { Adrenal } \\
\text { Ovaries } \\
\end{array}$ & & $\begin{array}{r}29.50 \\
72.80 \\
19.80 \\
229.70 \\
312.50 \\
\end{array}$ & $\begin{array}{r}1.90 \\
4.10 \\
1.50 \\
67.80 \\
16.70\end{array}$ & $\begin{array}{r}25.80 \\
70.00 \\
17.50 \\
221.70 \\
275.20\end{array}$ & $\begin{array}{r}2.20 \\
1.50 \\
1.80 \\
31.50 \\
17.90\end{array}$ & $\begin{array}{r}21.00 \\
70.80 \\
16.25 \\
130.00 \\
195.30\end{array}$ & $\begin{array}{c}1.10^{*} \\
.86 \\
1.30 \\
36.90 \\
20.50^{* *}\end{array}$ & $\begin{array}{r}23.0 \\
71.8 \\
10.5 \\
183.5 \\
199.5\end{array}$ & $\begin{array}{l}1.9 * \\
2.3 \\
1.2 * * \\
11.1 \\
17.8 * *\end{array}$ \\
\hline \multicolumn{10}{|c|}{ Number of Fertile Rats } \\
\hline \multicolumn{2}{|c|}{ Group CC } & \multicolumn{2}{|c|}{ Group CE } & \multicolumn{3}{|c|}{ Group EC } & \multicolumn{3}{|c|}{ Group EE } \\
\hline Male & Female & Male & Female & \multicolumn{2}{|c|}{ Male } & Female & Male & \multicolumn{2}{|c|}{ Female } \\
\hline $2 / 4$ & $2 / 4$ & $4 / 4$ & $1 / 4$ & \multicolumn{2}{|c|}{$0 / 4$} & $1 / 4$ & $1 / 4$ & \multicolumn{2}{|c|}{$1 / 4$} \\
\hline
\end{tabular}

Note-Shown are the mean number of days ( \pm SEs) elapsing between rats' being placed together and the appearance of sperm plugs, the weight of reproductive organs (organ weight/body weight $\left.\times 10^{4}\right)$, and fertility data. Animals were left together for a maximum of 40 days. If no plug was observed by that time, the latency was scored as 40 . (See text for description of groups.)

${ }^{*} p<.05$, relative to Group $C C . \quad{ }^{* *} p<.01$, relative to Group $C C$.

propylene glycol. This phase of the study, lasting 30 days, terminated when the animals were approximately 120 days of age. Two months later, 32 of these animals were used in the present study to examine their reproductive behavior and their of fspring.

When all animals were approximately 6 months of age, each of four males from each of the four groups was housed with one castrated male rat and one naive female rat (Smart \& Dobbing, 1971) and each of four females of each of the five groups was housed with two naive males. The presence of sperm plug was taken as evidence of copulation and was designated Day 0 of pregnancy. At this time, the impreganted females were placed individually into breeding cages, and, except for daily weighings, the animals were not interfered with. If no sperm plugs appeared within $\mathbf{4 0}$ days, the male and female subjects were separated. Once the $F_{2}$ rat pups were born, they were weighed daily until 1 week after weaning and underwent a series of daily reflex and developmental tests, including righting, free-fall righting, incisor eruption, eye opening, ear unfolding, cliff avoidance, and visual placing (Fried, 1976; Merari et al., 1973). Observations pertaining to litter size, cogenital malformations, fetal resorptions, and reproductive organ weights were also made. The latter dependent variable was measured 23 days after the male and female rats were separated.

\section{RESULTS AND DISCUSSIONS}

The fertility data are summarized in Table 1 . As both the male and female rats demonstrated the same trends, the results are not discussed separately. The data, analyzed by a chi square, indicate that the $F_{1}$ rats exposed to marihuana smoke during embryological development may be less fertile than the CC control group. This is demonstrated both by the significantly longer time required for the EC group $(p<.05)$ to mate and a similar trend in the EE group $(\mathrm{p}<.10)$ and by significantly fewer successful pregnancies and impregnations in these two groups as contrasted to the two groups that received placebo smoke during fetal development $(p<.05)$. The weight of the reproductive organs of the $F_{1}$ rats are presented in Table 1. The data were examined by an analysis of variance with post hoc group compari- sons being made by Tukey's honestly significant difference test with appropriate adjustments when groups have an unequal number of subjects (Kirk, 1968). In the males, the seminal vesicles of the $\mathrm{EE}$ and EC animals weighed significantly less than those of the CC ( $p<.05$ in both cases) and the prostate gland of the EE group was significantly reduced compared to the $C C$ animals $(p<.01)$. Interestingly, there were no differences among the groups with respect to testicular weight, thus indirectly supporting earlier reports of testicular weight recovery (Dixit et al., 1974). The weights of the ovaries were markedly reduced in the female EC and EE animals relative to the other two groups $(p<.001)$, and the adrenal glands showed a similar trend. A point biserial analysis (Ferguson, 1959) of the size of the various reproductive organs and fertility indicated a significant correlation between the weights of the ovaries $\left(r_{p b i}=.666, p<.01\right)$, adrenals $\left(r_{p b i}=.632, p<.01\right)$, and fertility, and a similar trend for the seminal vesicles $\left(r_{p b i}=.435, \mathrm{p}<.08\right)$.

In the EC ${ }^{1}$ and EE groups, the females that did give birth had a gestation period that was $2-21 / 2$ days longer and a reduced maternal weight gain in comparison to the other two groups $(\bar{X}=92 \mathrm{~g}$ vs. $104 \mathrm{~g})$. As the data are based on only three litters, statistical significance was not reached, but both trends have been reported elsewhere when THC was administered directly to a gravid animal (Banerjee et al., 1975; Borgen et al., 1971; Borgen et al., 1973; Pace et al., 1971). No gross malformations, stunting, or differences in litter size were observed in any of the litters, but there were more resorptions in the EC and EE groups (2/8 in each case) than in the CE and CC group $(0 / 16)$.

There were marked differences in the birth weights of the $F_{2}$ litters born to the four groups, and these differences persisted in both sexes beyond weaning. 
Table 2

$\mathrm{F}_{2}$ Weights

\begin{tabular}{|c|c|c|c|c|c|c|c|c|c|c|c|c|c|c|c|c|}
\hline \multirow[b]{3}{*}{ Day } & \multicolumn{4}{|c|}{ Group CC } & \multicolumn{4}{|c|}{ Group CE } & \multicolumn{4}{|c|}{ Group EC } & \multicolumn{4}{|c|}{ Group EE } \\
\hline & \multicolumn{2}{|c|}{ Male } & \multicolumn{2}{|c|}{ Female } & \multicolumn{2}{|c|}{ Male } & \multicolumn{2}{|c|}{ Female } & \multicolumn{2}{|c|}{ Male } & \multicolumn{2}{|c|}{ Female } & \multicolumn{2}{|c|}{ Male } & \multicolumn{2}{|c|}{ Female } \\
\hline & Mean & SE & Mean & SE & Mean & SE & Mean & SE & Mean & SE & Mean & SE & Mean & SE & Mean & SE \\
\hline 1 & 5.79 & .44 & 5.7 & .74 & 5.8 & .35 & & .75 & 5.36 & .43 & & .66 & 5.37 & .99 & 5.20 & .58 \\
\hline 10 & & .52 & & & & .24 & 20 , & .6 & & .63 & & .75 & & & & .45 \\
\hline 21 & 52.30 & .51 & 52.70 & 1.13 & 52.50 & 1.13 & 52.70 & .61 & 44.50 & 1.16 & 43.40 & .48 & 43.60 & .39 & 43.20 & .58 \\
\hline 30 & 73.20 & 1.06 & 73.10 & .72 & 71.20 & .75 & 71.70 & .45 & 64.50 & .31 & 62.80 & .29 & 63.50 & .31 & 63.10 & .90 \\
\hline
\end{tabular}

Note-Shown are the mean weights in grams ( \pm SEs) of the $F_{2}$ animals. The pups were weaned on Day 22. On each day, the EC and $E E$ animals weighed significantly less $(p<.001)$ than the other two groups. (See text for description of groups.)

The results of Day 1, 10, 21, and 30 are presented in Table 2. On each of the days on which data were collected, the male and female offspring of the EC and EE animals weighed significantly less than the other two groups ( $p<.001$ in all cases). Of the reflexes and physiological development tested, only eye opening and incisor eruption was differentially affected in the pups, with the EC and EE offspring being significantly slower $(p<.001)$ than the litters of the other two groups. This is a particularly striking finding as it was these two reflexes which were retarded in their appearance in the EC and EE animals when they were pups (Fried, 1976).

Overall, the data lead us to conclude that there is a marked decrease in fertility, presumably resulting from the reduced reproductive organs and the resulting hormonal changes, in male and female rats that are exposed to marihuana smoke during fetal development and THC injections 2 months prior to mating. This reduction in reproductive behavior is much more pronounced than that which arises following exposure to smoke from placebo material prenatally and chronic injections of THC 2 months before mating. Moreover, the offspring of the EC and EE animals were consistently lighter and slower in some of their physiological development. Both the males and females of the $F_{1}$ generation produced offspring that were retarded in their growth and development. This would suggest that the effect of marihuana inhalation was genetic in nature rather than merely a hormonal change in the females of the $F_{1}$ generation. What must be emphasized about these latter results is that they are a function of cannabis smoke administered two generations earlier. One characteristic of humans that smoke marihuana regularly is that their age span coincides with their peak reproductive years (Ledain, 1972); thus, these results, although obtained with rodents, indicate a potential area of significance with respect to cannabis usage.

\section{REFERENCES}

Banerjee, B. N., Galbreath, C., \& Sofia, R. D. Teratologic evaluation of synthetic $\Delta^{9}$-THC in rats. Teratology, 1975, 11, 99-102.
Borgen, L. A., Davis, W. M., \& Pace, H. B. Effects of synthetic delta-9-THC on pregnancy and offspring in the rat. Toxicology \& Applied Pharmacology, 1971, 20, 480-486.

Borgen, L. A., Davis, W. M., \& PACE, H. B. Effects of prenatal tetrahydrocannabinol on the development of rat offspring. Pharmacology, Biochemistry \& Behavior, 1973, 1, 203-206.

Braude, M. C. Genetics and reproduction. In M. C. Braude \& S. Szara (Eds.), Pharmacology of marihuana. New York: Raven Press, 1976.

Cushman, P. Plasma testosterone levels in healthy male marihuana smokers. American Journal of Drug \& Alcohol Abuse, 1975, 2, 269-275.

Dixit, V. P., Sharma, V. N., \& Lohiya, N. K. The effects of chronically administered cannabis extract on the testicular function of mice. European Journal of Pharmacology, 1974, 26, 111-114.

Ferguson, G. A. Statistical analysis in psychology and education. New York: McGraw-Hill, 1959.

Fisher, G., \& Brickman, H. R. Multiple drug use of marijuana users. Diseases of the Nervous System, 1973, 34, 40-43.

Fleischman, R. W., Hayden, D. W., Rosenkrantz, H., \& Braude, M. C. Teratologic evaluation of $\Delta^{9}$-tetrahydrocannabinol in mice, including a review of the literature. Teratology, 1975, 12, 47-50.

Fried, P. A. Short and long-term effects of pre-natal cannabis inhalation upon rat offspring. Psychopharmacology, 1976, 50, 285-291.

Fried, P. A., \& Nieman, G. W. Inhalation of cannabis smoke in rats. Pharmacology, Biochemistry \& Behavior, 1973, 371-378.

Geber, W. F., \& Schramm, L. C. Effect of marihuana extract on fetal hamsters and rabbits. Toxicology \& Applied Pharmacology, 1969, 14, 276-282. (a)

Geber, W. F., \& Schramm, L. C. Teratogenicity of marihuana extract as influenced by plant origin and seasonal variation. Archives internationales de Pharmacodynamie et de Thérapie, 1969, 177, 224-230. (b)

Gianutsos, G., \& Abbatiello, E. R. The effect of pre-natal cannabis sativa on maze learning ability in the rat. Psychopharmacologia, 1972, 27, 117-122.

Grilly, D. M., Ferraro, D. P., \& Braude, M. C. Observations on the reproductive activity of chimpanzees following longterm exposure to marihuana. Pharmacology, 1974, 11, 304-307.

Harbison, R. D., \& Mantilla-Plata, B. Pre-natal toxicity, maternal distribution and placental transfer of tetrahydrocannabinol. Journal of Pharmacology \& Experimental Therapeutics, 1972, 180, 446-453.

JonejA, M. G. A study of teratological effects of intravenous, subcutaneous and intragastric exposure to $\Delta^{9}$-tetrahydrocannabinol in mice. Toxicology \& Applied Pharmacology, 1976, 36, 151-162.

Keplinger, M. L., Wright, P. L., Haley, S. L., Plank, J. B., Braude, M. C., \& Calandra, J. C. The effects of natural and synthetic delta-9-tetrahydrocannabinol on repro- 
ductive and lactation performance in albino rats. Toxicology \& Applied Pharmacology, 1973, 22, 449.

KIRK, R. E. Experimental design: Procedures for the behavioral sciences. Belmont, Calif: Wadsworth, 1968.

Kolodny, R. C., Masters, W. H., Kolodner, R. M., \& Toro, G. Depression of plasma testoterone levels after chronic intensive marihuana use. New England Journal of Medicine, 1974, 290, 872-874.

LEDAIN, G. Cannabis: $A$ report to the commission of inquiry into the non-medical use of drugs. Ottawa: Information Canada, 1972.

Ling, G. M., Thomas, J. A., Usher, D. R., \& Singhal, R. L. Effects of chronically administered $\Delta^{1}$-tetrahydrocannabinol of (Sic.) adrenal and gonadal activity of male rats. International Journal of Clinical Pharmacology, 1973, 7, 1-5.

Mantilla-Plata, B., Clewe, G. L., \& Harbison, R. D. Teratogenic and mutagenic studies for $\Delta^{9}$-tetrahydrocannabinol. Federation Proceedings, 1973, 32, 746.

Mantilla-Plata, B., Clewe, G. L., \& Harbison, R. D. $\Delta^{9}$-tetrahydrocannabinol induced changes in pre-natal growth and development of mice. Toxicology \& Applied Pharmacology, 1975, 33, 333-340.

Marihuana and Health. Fifth Annual Report to Congress, Department of Health, Education and Welfare. Washington, D.C: Government Printing Office, 1975.

Mendelson, J. H., Kuehnle, J., Ellingboe, J., \& Babor, T. F. Plasma testosterone levels before, during and after chronic marihuana smoking. New England Journal of Medicine, 1974, 291, 1051-1055.

Merari, A., Barek, A., \& Plaves, M. Effects of $\Delta^{1}{ }^{2}$-tetrahydrocannabinol on copulation in the male rat. Psychopharmacologia, 1973, 28, 243-246.
Miras, C. J. Some aspects of cannabis action. In G. E. W. Wolstenholme \& J. Knight (Eds.), Hashish: Its chemistry and pharmacology. Boston: Little, Brown, 1965.

Pace, H. B., Davis, W. M., \& Borgen, L. A. Teratogenesis and marihuana. Annals of the New York Academy of Science, $1971,191,123-131$.

Persuad, T. V. N., \& Ellington, A. C. Cannabis in early pregnancy. Lancet, 1967, II, 1306.

Persaud, T. V. N., \& Ellington, A. C. Teratogenic activity of cannabis resin. Lancet, 1968, II, 406-407.

Smart, J. L., \& DobBing, J. Vulnerability of developing brain. II. Effects of early nutritional deprivation on reflex ontogeny and development of behavior in the rat. Brain Research, 1971, 28, 85-95.

Solomon, J., Cocchia, M. A., Gray, R., Shattuck, D., \& Vossmer, A. Utertrophic effect of delta-9-tetrahydrocannabinol in ovariectomized rats. Science, 1976, 192, 559-561.

Wright, P. L., Smith, S. H., Keplinger, M. L., Calandra, J. C., \& Braude, M. C. Reproductive and teratologic studies with $\Delta^{9}$-tetrahydrocannabinol and crude marihuana extract. Toxicology \& Applied Pharmacology, 1976, 38, 223-235.

\section{NOTE}

1. In this discussion, the designations $\mathrm{CC}, \mathrm{CE}, \mathrm{EC}$, and $\mathrm{EE}$ females refer to both those females that were in the previous (Fried, 1976) study and to females impregnated by males of the various groups of that study.

(Received for publication December 1, 1978; revision accepted July $10,1979$. 